\title{
INTELLECTUAL CAPITAL DAN ABNORMAL RETURN SAHAM
}

\author{
Aulia Kartika Putri ${ }^{1}$, Erina Sudaryati ${ }^{2}$ \\ Universitas Airlangga
}

\begin{abstract}
$\underline{\text { Aulia.kartika.putri-2016@feb.unair.ac.id }}$, Erina.sudaryati@feb.unair.ac.id ${ }^{2}$
\end{abstract}
\begin{abstract}
ABSTRAK : Penelitian ini bertujuan untuk mengetahui pengaruh Intellectual Capital (IC) yang diukur menggunakan Value Added Intellectual Capital (VAICTM) yang mempunyai tiga komponen yaitu Value Capital (VACA-value added capital employed), human capital (VAHU-value added human capital), dan structural capital (STVA-structural capital value added) terhadap reaksi pasar saham yang diproksikan dengan melihat Average Abnormal Return saham pada perusahaan LQ-45. Metode yang digunakan pada penelitian yaitu analisis regresi linier berganda dengan alat anlisis SPSS 17. Teknik pengambilan sampel dengan menggunakan purposive sampling, dan berdasrkan kriteria yang telah ditentukan maka jumlah sampel sebanyak 17 sampel perusahaan LQ-45 selama tahun 2013-2015. Variabel dependen pada penelitian yaitu average abnormal return saham. Variabel independent pada penelitian yaitu tiga komponen VAIC. Hasil penelitian menunjukkan jika VACA berpengaruh terhadap average abnormal return saham dan variabel VAHU dan STVA tidak memiliki pengaruh terhadap average abnormal return saham.
\end{abstract}

Kata Kunci : intellectual capital, return saham, value added capital employed, value added human capital, structural capital value added

\section{Pendahuluan}

Pada era globalisasi, era yang telah maju ini semua sektor banyak yang mengalami perkembangan. Hampir semua sektor akan berlomba-lomba agar industrinya meningkat dan mengikuti perkembangan. Perkembangan yang terus mningkat pesat diidentifikasi dengan melihat kemajuan di bidang teknologi. Adanya persaingan yang keras dan sesuai aturan dengan adanya pertumbuhan inovasi yang signifikan terjadi pada sektor bisnis. Perkembangan yang berkelanjutan menjadikan perusahaan berusaha untuk terus mengevaluasi dan meningkatkan kinerjanya agar bertahan dalam melangsungkan kegiatan usahanya. Karakteristik ekonomi dari dasar pengetahuan (knowledge management), menegaskan jika suatu perusahaan dapat berhasil dikarenakan adanya penciptaan transformasi dan kapitalisasi dari pengetahuan yang dimiliki (Sawarjuwono dan Kadir, 2003). Pengetahuan dasar akan sangat diperlukan agar perusahaan lebih berusaha untuk menciptakan hal baru dan mengelola pengetahuan demi tercapainya tujuan perusahaan, sebuah perusahaan yang berusaha terus untuk maju akan merumuskan dan membuat berbagai macam strategi agar pengetahuan yang dimilikinya dapat dimanfaatkam secara maksimal dan tepat guna. Pentingnya hal ini membuat perusahaan sadar untuk mengelola kepemilikan sumber daya perushaan sebagai faktor yang paling penting dalam mempertahankan keunggulan perusahaan dibanding para pesaingnya.

Akhirnya, perusahaan mengubah strateginya menjadi knowledge based business sebagai cara perusaahaan meningkatkan efisiensi dan efektivitas penggunaan sumber daya yang lainnya. Nilai lebih sebuah perusahaan dapat dihasilkan dengan adanya modal intelektual yang dapat diperoleh perusahaan dengan cara pengembangan pada budaya perusaahaan atau kemampuan perusahaan dalam memotivasi karyawannya. Banyak opini yang menjelaskan jika aset perusahaan yang paling berharga yaitu dengan memiliki Sumber Daya Manusia (SDM) khusunya sumber daya intellectual capital. Semua aset berwujud yang dimiliki oleh perusahaan akan dikendalikan oleh manusia sehingga kemampuan manusia dapat mempengaruhi operasional perusahaan. saat ini intellectual capital (IC) telah di implementasikan hingga 
e-NARODROID

Volume IV, Juli 2018

ISSN 2407-7712

Halaman 54-59

sampai pada tahap lingkungan bisnis. Peluang untuk menjadi pemenang di pasar global akan diraih oleh negara-negara yang memiliki sumber daya manusia (SDM) yang berkualitas.

Definisi Intellectual Capital (IC) menurut berbagai sumber dapat diartikan yaitu adanya penambahan dari masing-masing komponen yang dapat memberikan kontribusi nilai tambah bagi perusahaan. Intellectual Capital (IC) mempunyai tiga komponen utama yaitu (1). Human Capital (HC) mempresentasikan individual knowledge stock suatu organisasi yang dipresentasikan oleh karyawannya. (2). Structural Capital (SC) meliputi seluruh non-human storehouse of knowledge dalam sebuah organisasi maupun perusahaan termasuk dalam hal ini adalah database, organizational charts, process manuals, strategies, routines dan segala hal yang membuat nilai perusahaan lebih besar dari nilai materinya. Dan (3). Customer Capital (CC) merupakan pengetahuan yang tidak dapat lepas dalam marketing channels dan customer relationship dimana suatu organisasi mengembangkan hal tersebut melalui proses berbisnis. Tiga komponen tersebut masing-masing mempunyai peran dalam menciptakan intellectual capital perusahaan yang akhirnya akan menentukan nilai perusahaan. Ulum (2008:78) berpendapat bahwa market value terjadi karena masuknya konsep modal intelektual, yang merupakan faktor utama dan dapat meningkatkan nilai perusahaan. Sejalan dengan nilai perusahan yang meningkat, kinerja keuangan perusahaan dapat meningkat yang mengakibatkan laba perusahaan menjadi naik. Ramadhani (2013) menjelaskan jika besarnya laba yang diperoleh perusahaan dapat tercapai jika kinerja keuangan perusahaan tersebut bagus. Pendapatan yang dihasilkan oleh perusahaan akan dinilai oleh investor sebagai harapan dalam menerima tingkat bagi hasil yang tinggi.

Salah satu strategi yang harus dikembangkan saat membangun bisnis di sebuah perusahaan yaitu menjaga eksistensinya dengan cara pencarian pendanaan yang ditujukan dengan dasar untuk perbaikan aktivitas operasional perushaan. Penerbitan saham dapat menjadi salah satu cara yang dapat dilakukan oleh perusahaan agar penambahan dana untuk aktivitas operasi dapat tercukupi. Seorang investor yang akan berinvestasi pasti memiliki tujuan untuk mendapatkan return atas invesatasi yang investor tempatkan pada perusahaan. sebelum berinvestasi dibutuhkan informasi yang akurat dari laporan keuangan perusahaan. disisi lain, para pengguna laporan keuangan seperti investor ini membutuhkan informasi yang bersifat kuantitatif dan kualitatif sebagai evaluasi kinerja perusahaan serta informasi mengenai modal intelektual yang dimiliki perusahaan. Seiring dengan meningkatnya kebutuhan akan pengungkapan intellectual capital sebagai penggerak nilai perusahaan sedangkan adanya nilai kesulitan dalam mengukur intellectual capital secara langsung muncullah pengukuran intellectual capital secara tidak langsung dengan menggunakan Value Added Intellectual Capital (VAICTM), yaitu suatu ukuran untuk menilai efisiensi dari nilai tambah sebagai hasil dari kemampuan intelektual perusahaan. Value Added Intellectual Capital (VAIC ${ }^{\text {TM}) ~ m e m u l a i ~}$ dengan sebuah kemampuann sebuah perusahaan untuk menciptakan nilai tambah (value added). Value Added (VA) ditetapkan sebagai indikator ukuran yang paling obyektif untuk menganalisis dan menilai keberhasilan bisnis serta dapat menunujukkan kemampuan perusahaan dalam menciptakan nilai (value creation).

Munculnya fenomena mengenai intellectual capital menyebabkan meningkatnya ketertarikan dari banyak kalangan. Mereka ingin mendapatkan banyak informasi yang berkaitan dengan pengelolaan, identifikasi, pengukuran, serta pelaporan intellectual capital. Mereka juga menginginkan informasi yang lebih lengkap, detail dan terperinci mengenai analisis intellectual capital dan pengaruhnya. Perusahaan yang memiliki standard kinerja intellectual capital yang baik akan mempublikasikan intellectual capital yang dimiliki nya sebagai keunggulan perushaan karena tingginya tingkat pengungkapan dapat menyebabkan semakin tinggi kinerja intellectual capital. Akhirnya, investor akan percaya untuk berinvestasi pada perusahan tersebut. Saat investor mengambil keputusan investasi hal ini akan menyebakan perubahan pada harga saham dah akhirnya mempengaruhi abnormal return saham. Sir (2010) melakukan penelitian tentang intellectual capital dan abnormal return saham yang hasilnya menunjukkan bahwa intellectual capital berpengaruh secara signifikan terhadap abnormal return saham. Penelitian Ulum (2008); Tan, Plowman, \& Hancock (2007); dan Firrer, \& William (2003) menjadikan intellectual capital untuk melihat pengaruhnya 
terhadap kinerja keuangan. Penelitian ini melihat pengaruh intellectual capital terhadap abnormal return saham pada perusahaan yang terdaftar pada LQ-45 di Bursa Efek Indonesia (BEI)

\section{Tinjauan Pustaka}

Menggunakan teori stakeholder yang memfokuskan pada posisi seorang stakeholder yang diperkirakan memiliki pengaruh bagi perusahaan. Pengaruh yang diciptakan oleh para kelompok stakeholder akan menjadi pertimbangan penting bagi suatu perusahaan dalam mengambil keputusan pengungkapan maupun tidak mengungkapkan sebuah informasi yang ada pada laporan keuangan. Stakeholder tidak hanya sebatas para pelaku usaha namun juga termasuk pemegang saham perusahaan, masyarakat, dan lingkungan dalam segala aspek operasional perusahaan (Belkaoui, 2003). Definisi Intellectual capital pada penelitian ini dirangkum dari berbagai teori ekonomi yang mendefinisikan bahwa Intellectual capital sebagai suatu materi intelektual yang jenisnya dapat berupa sebuah informasi, ilmu pengetahuan, inovasi baru, kecerdasan dan pengalaman yang dapat dimanfaatkan dalam menghasilkan aset yang mempunyai nilai tambah dan memberikan keunggulan bersaing.

Penelitian terdahulu terkait intellectual capital dilakukan oleh Chen, Cheng, Hwang (2005) menggunakan sebuah model Pulic (VAICTM) untuk menguji suatu hubungan antara IC dengan nilai pasar dan kinerja keuangan perusahaan. Hasilnya menunjukkan bahwa IC berpengaruh positif terhadap nilai pasar dan kinerja keuangan perusahaan. Sejalan dengan penelitian yang dilakukan Ulum (2008) terkait IC dan kinerja perusahaan dengan menggunakan metode VAIC untuk penelitian dalam tiga aspek pengaruh, yaitu pengaruh intellectual capital dengan kinerja perusahaan, kinerja keuangan perusahaan dimasa yang akan datang, serta pengaruh tingkat pertumbuhan kinerja keuangan perusahaan di masa yang akan datang. Hasilnya menunjukkan terdapat hubungan signifikan yang positif antara intellectual capital dengan kinerja perusahaan. berdasarkan penelitian yang telah dilakukan sebelumnya, maka penelitian saat ini akan melihat apakah intellectual capital berpengaruh terhadap pasar saham. Hipotesis yang diuji pada penelitian ini yaitu:

H1: Value Added Capital Employement berpengaruh terhadap average abnormal return saham

H2: Value Added Human Capital berpengaruh terhadap average abnormal return saham

H3: Structural Capital Value Added berpengaruh terhadap average abnormal return saham

\section{METODOLOGI PENELITIAN}

Jenis penelitian ini adalah penelitian kuantitatif. Sampel ditetapkan dengan menggunakan purposive sampling. kriteria yang digunakan peneliti sebagai berikut :

1. Perusahaan LQ-45 terdaftar di BEI telah menerbitkan laporan keuangan berturut-turut dari tahun 20132015.

2. Perusahaan LQ-45 terdaftar di BEI yang membagikan sahamnya berturut-turut dari tahun 2013-2015.

3. Perusahaan LQ-45 yang mencantumkan beban gaji di laporan keuangan berturut-turut dari tahun 20132015.

Data yang dikumpulkan meliputi laporan keuangan tahunan perusahaan LQ-45 yang menjadi sampel penelitian. Teknik pengumpulan data dalam penelitian ini menggunakan teknik dokumentasi yang berasal dari Pusat Referensi Pasar Modal Bursa Efek Indonesia (www.idx.co.id) dan yahoo finance. Penelitian ini menggunakan variabel independent intellectual capital yang diukur secara tidak langsung dengan menilai efisiensi dari nilai tambah (value added) sebagai hasil dari kemampuan intelektual perusahaan (Value Added Intellectual Coefficient VAIC $\left.{ }^{\mathrm{TM}}\right)$.

Komponen utama dari $\mathrm{VAIC}^{\mathrm{TM}}$ dapat dilihat dari sumber daya perusahaan, yaitu physical capital (VACA-value added capital employed), human capital (VAHU-value added human capital), dan structural capital (STVA-structural capital value added). Pengukuran intellectual capital menggunakan tiga proksi, yaitu: (1) VACA merupakan perbandingan antara value added (VA) dengan total ekuitas perusahaan (CE) yang dimanfaatkan dalam aset tetap dan lancar suatu perusahaan (Pulic, 1998 dalam Ulum et al., 2008), (2) VAHU menunjukkan berapa banyak VA dapat dihasilkan dengan dana yang dikeluarkan untuk tenaga 
kerja.(3) STVA mengukur jumlah modal struktural (SC) yang dibutuhkan untuk menghasilkan 1 rupiah dari value added (VA) dan merupakan indikasi bagaimana keberhasilan modal struktural (SC) dalam penciptaan nilai. Variabel dependen yaitu average abnormal return saham yang diukur dengan menghitung Abnormal return yang merupakan selisih dari return aktual dengan expected return yang dihitung dalam tiap tahunnya yaitu abnormal return tahun 2013, 2014, dan 2015 selanjutnya dirata-rata dan dibagi dengan jumlah keseluruhan. Selanjutnya, semua variabel di analisis menggunakan analisis regresi linier berganda. Berikut rumus menghitung abnormal return :

$$
\mathrm{AR}_{\mathrm{i}, \mathrm{t}}=\mathrm{R}_{\mathrm{i}, \mathrm{t}}-\mathrm{R}_{\mathrm{m}, \mathrm{t}}
$$

\section{Dimana:}

$$
\begin{array}{ll}
\mathrm{AR}_{\mathrm{i}, \mathrm{t}} & =\text { abnormal return perusahaan i pada periode ke- } \mathrm{t} \\
\mathrm{R}_{\mathrm{i}, \mathrm{t}} & =\text { Return perusahaan pada periode ke-t } \\
\mathrm{R}_{\mathrm{m}, \mathrm{t}} & =\text { return pasar pada periode ke- } \mathrm{t}
\end{array}
$$

\section{HASIL DAN ANALISIS}

Data yang telah ditabulasi di olah dengan menggunakan Alat Uji SPSS 17. Alat uji SPSS ini digunakan untuk menguji pengaruh masing-masing variabel indpenden VACA, VAHU, STVA terhadap

\begin{tabular}{|c|c|c|c|c|c|}
\hline & & \multicolumn{2}{|c|}{$\begin{array}{c}\text { Unstandardized } \\
\text { Coefficients }\end{array}$} & \multirow[b]{2}{*}{$\mathrm{t}$} & \multirow[b]{2}{*}{ Sig. } \\
\hline \multicolumn{2}{|c|}{ Model } & B & Std. Error & & \\
\hline \multirow[t]{4}{*}{1} & (Constant) & -2577.581 & 3262.877 & -.790 & .434 \\
\hline & VACA & 8436.080 & 2770.769 & 3.045 & .004 \\
\hline & VAHU & -.628 & .549 & -1.145 & .258 \\
\hline & STVA & 1541.648 & 4037.144 & .382 & .704 \\
\hline
\end{tabular}
variabel dependen average abnormal return saham. Berikut hasil analisis regresi linier :

\section{Tabel 1}

\section{Analisis Regresi}

Sumber : diolah

Dependent Variable: Average Abnormal Stock Return

Tabel 1 menunjukkan nilai signifikansi variabel VACA sebesar $0.004<0.05$ artinya VACA berpengaruh terhadap average abnormal return saham. Saat sebuah unit Capital Employed menghasilkan return yang lebih besar di sebuah perusahaan daripada perusahaan kompetitor yang lainnya, maka perusahaan tersebut menunjukkan jika ia memiliki pemanfaatan yang lebih baik pada indikator Capital Employed-nya (Daud \& Amri, 2008). Nilai VACA yang tinggi memiliki hubungan poitif dengan return karena hal ini mengindikasikan bahwa asset berwujud yang dimiliki oleh perusahaan LQ-45 merupakan suatu asset yang dapat meningkatkan kinerja perusahaan karena customer capital perusahaan LQ-45 muncul dalam bentuk proses belajar, akses, dan kepercayaan. Saat sebuah perusahaan memutuskan berinvestasi dari perusahaan tersebut, maka keputusan didasarkan pada kualitas hubungan mereka, harga, dan spesifikasi teknis perusahaan. Semakin baik hubungannya, semakin besar peluang rencana berinvetasi terjadi, dan hal 
ini semakin besar peluang perusahaan meningkatkan return dari kejadian oengungkapan IC pada pihak eksternal karena jadi berdampak pada abnormal return saham perusahaan tersebut.

Variabel VAHU dan STVA tidak memiliki pengaruh terhadap average abnormal return saham karena nilai signifikansi $>$ dari 0.05 yaitu VAHU $0.258>0.05$ dan STVA $0.704>0.05$. Artinya, pada perushaaan LQ-45 yang diuji pada penelitian ini kurang memiliki Human Capital serta kontribusi structural capital (SC) dalam pembentukan nilai perusahaan tidak mempengaruhi return saham perushaan tersebut. Variabel VAHU berdasarkan hasil uji regresi dapat diartikan bahwa human capital kemungkinan telah dimaksimalkan dalam perusahaan namun tidak memberikan memanfaat yang signifikan dalam perusahaan. hal ini dapat diperkirakan karena perusahaan tidak membutuhkan sebuah inovasi terbaru yang mungkin sebenarnya ada pada human capital itu sendiri. Karena perusahaan LQ-45 memiliki likuiditas tinggi tentunya operasional perusahaan bekerja terus sesuai permintaan konsumen. Dengan likuiditas tinggi ini LQ-45 lebih condong pada sistem manajemen operasional. Lain halnya dengan variabel STVA yang tidak memiliki pengaruh pada abnormal return karena structural capital value added merupakan nilai-nilai dari infrastruktur organisasi dan jenis pengetahuan yang tersimpan dalam bentuk manual, pedoman, konsep, maupun sistem informasi yang ada dalam perusahaan sehingga dapat menciptakan suatu efektifitas dan efisiensi dalam perusahaan.

\section{KESIMPULAN}

Berdasarkan hasil penelitian yang telah dilakukan mengenai pengaruh intellectual Capital terhadap average abnormal return saham, dapat disimpulkan jika Value Added Capital Employed (VACA) berpengaruh positif terhadap abnormal return sedangkan variabel VAHU dan STVA tidak memiliki pengaruh terhadap abnormal return. Secara general ketga variabel VACA $<$ VAHU, dan STVA secara Bersama-sama dapat mempengaruhi abnormal return. Bagi peneliti selanjutnya yang hendak mengkaji Intellectual Capital secara lebih mendalam dapat menambah objek penelitian serta menggolongkan IC pada perusahaan High-IC ataupun Low-IC dalam satu sektor perusahaan karena penelitian ini menggunakan perusahaan LQ-45 yang dimana terdapat berbagai jenis sector perusahaan likuiditas di Indonesia

\section{DAFTAR PUSTAKA}

Abdolmohammadi, M.J. 2005. "Intellectual Capital Disclosure and Market Capitalization". Journal of Intellectual Capital. Vol. 6 No. 3. Pp. 397-416.

Belkaoui, R. A. 2003. "Intellectual Capital and Firm Performance of US Multinational Firms: a Study of The Resource-Based and Stakeholders Views". Journal of Intellectual Capital. Vol. 4 No. 2. pp 215226.

Bontis, N., Keow, W.C.C. and Richardson, S. 2000. Intellectual capital and Business Performance in Malaysian Industries. Journal of Intellectual Capital Vol. 1 No. 1. Pp. 85-100.

Brennan, N. 2000. Reporting Intellectual Capital in Annual Reports: Evidience from Ireland. Accounting, Auditing \& Accountability Journal 14 (4): 423-436.

Chen, M-C., S-J Cheng, dan Y Hwang. 2005. An. Empirical Investigation of the Relationship Beetwen Intellectual Capital and Firm's Market Value and Financial Performance. Journal of Intellectual Capital Vol. 6 No. 2. Pp. 159-176. 
Firer, Steven and S. Mitchell Williams (2003),'Intellectual Capital and Traditional Measure of Corporate Performance" Journal of Intellectual Capital. Vol. 4, No. 3. Page 348-60.

Ramadhani, I. (2013). Pengaruh Penerbitan Obligasi Syariah Terhadap Profitabilitas. Etikonomi, 12(2).

Sawarjuwono, T. dan A.P. Kadir. 2003. Intellectual Capital: Perlakuan, Pengukuran dan Pelaporan (Sebuah Library Research). Jurnal Akuntansi dan Keuangan. Vol. 5. No. 1. Pp. 31-57.

Sir, J., Subroto, B., \& Chandrarin, G. (2010). Intellectual Capital dan Abnormal Return Saham. Simposium Nasional Akuntansi XIII.

Tan, H.P., D. Plowman, dan P.Hancock. 2007. Intellectual Capital and Financial Returns of Companies. Journal of Intellectual Capital Vol.8 No.1. pp. 76-95.

Ulum, I., I. Ghozali dan A. Chariri. 2008. Intellectual Capital dan Kinerja Keuangan Perusahaan; Suatu Analisis dengan Pendekatan Partial Least Squares. Simposium Nasional Akuntansi XI. Pontianak: 23-24 Juli.

Yuniasih, N.W., D.G.Wirama, dan I.D.N. Badera. 2011. Pengaruh Modal Intelektual pada Kinerja Perusahaan. Jurnal Ilmiah Akuntansi dan Bisnis 6(2). 